www.jmscr.igmpublication.org

Impact Factor (SJIF): 6.379

Index Copernicus Value: 71.58

ISSN (e)-2347-176x ISSN (p) 2455-0450

crossref DOI: https://dx.doi.org/10.18535/jmscr/v6i2.97

Journal Of Medical Science And Clinical Research

\title{
Intra Medullary Tuberculoma Presenting as Brown Sequard Syndrome with Concurrent Intradural Extramedullary Tuberculoma and Arachnoiditis
}

\author{
Authors
}

\section{Pratibha Prasad $^{1}$, Amita Bhargava ${ }^{2}$, Khichar Shubhakaran ${ }^{3}$}

${ }^{1}$ D.M. Neurology, Senior Resident, Department of Neurology, Dr. S.N. Medical College, Rajasthan

University Of Health Science, Jodhpur - 342001, Rajasthan, India

${ }^{2}$ D.M. Neurology, Professor and Head, Department of Neurology, Dr. S.N. Medical College, Rajasthan

University Of Health Science, Jodhpur - 342001, Rajasthan, India

${ }^{3}$ D.M. Neurology, Professor, Department of Neurology, Dr. S.N. Medical College, Rajasthan University Of

Health Science, Jodhpur - 342001, Rajasthan, India

\begin{abstract}
Intramedullary and intradural-extramedullary spinal tuberculomas causing spinal cord compression is an uncommon entity. We report an unique case of a 27-year-old Indian male patient on 4 drug antituberculous chemotherapy for tubercular meningitis, who presented after two months with rapidly progressive unilateral lower limb monoparesis with loss of pain and temperature in the contralateral limb but intact position and vibration sense. MRI spine showed a single intramedullary tuberculoma at D2-D3 level, might causing brown sequard syndrome, associated with multiple intradural-extramedullary tuberculomas in thoracic and cervical region with arachnoiditis. MRI brain showed no evidence of intracranial tuberculoma. In our case the patient was given high dose steroid to which he responded and later discharged on antituberculous therapy and oral steroids. This case is being reported owing to its rarity of its presentation as brown sequard syndrome and co-occurrence of both intramedullary and intradural-extramedullary tuberculomas in an immunocempetent patient.

Keywords: Intramedullary, Intradural-extramedullary Tuberculoma, Brown-Sequard-Syndrome.
\end{abstract}

\section{Introduction}

Tuberculosis still remains endemic in developing countries_such as Asia and Africa. The brain is more commonly affected than the spinal cord, the ratio being $42: 1$. This may be due to the relative masses of neural tissue in them. ${ }^{(1)}$ Intramedullary tuberculomas is a lesion extremelly rare seen only in 2 of 100, 000 cases of tuberculosis and 2 of 1000 cases of tuberculosis of central nervous systems disesase. ${ }^{(2)}$ Our patient, on two months of antitubercular therapy (ATT) for tubercular meningitis (TBM), presented with atypical brown sequard syndrome (BSS) who was later confirmed to be a case of concomitant intramedullary and intradural-extramedullary (IDEM) tuberculomas of spine with arachnoiditis. We report this case owing to its rarity of its presentation as atypical BSS and coexistence of both intramedullary and IDEM tuberculoma. 


\section{Case History}

A 27-year-old Indian man was admitted with a 4 month history of mild to moderate grade fever, progressive headache; nausea, vomiting for 2 weeks and altered sensorium for last 4 days. His previous medical and surgical history was insignificant. On examination, he was disoriented, febrile without any focal neurological deficits with blood pressure of 130/76 mm Hg. Neck rigidity was present. Laboratory investigations showed a WBC count of $8,300 / \mathrm{mm} 3$ (80\% neutrophils), hematocrit $46.7 \%$, ESR of $3 \mathrm{~mm} / \mathrm{h}$, glucose 94 $\mathrm{mg} / \mathrm{dl}$, urea $36 \mathrm{mg} / \mathrm{dl}$, alanine aminotransferase 16 IU/l. Serology of two blood cultures and HIV were negative. X-rays of chest and air sinuses, as well as a brain computerized tomography (CT) scan was insignificant. Mountoux was negative. CSF examination revealed a lymphocytic pleocytosis (348cells/mm3), elevated protein concentration (315 mg/dl), low glucose concentration $(21 \mathrm{mg} / \mathrm{dl})$. TBM was suspected and ATT with rifampicin $600 \mathrm{mg}$, isoniazid $300 \mathrm{mg}$, ethambutol $1,000 \mathrm{mg}$ and pyrazinamide 1,500 $\mathrm{mg}$, was commenced from the 3rd day of the patient's hospitalization. Simultaneously, intravenous mannitol and dexamethasone were also introduced. The MRI brain was normal and CT scan thorax was negative for any tuberculous pulmonary lesions. The isolation and identification of Mycobacterium tuberculosis from CSF after 3 weeks confirmed the initial diagnosis. The drug test showed susceptibility to all the major anti-TB regimens. The patient recovered and was discharged with instructions to continue the ATT (rifampicin $600 \mathrm{mg}$, isoniazid $300 \mathrm{mg}$, ethambutol $1,000 \mathrm{mg}$ and pyrazinamide $1,500 \mathrm{mg}$ ) with strict adherence.

2 months later he presented with 10 days history of severe burning sensation of right lower limb and rapidly progressive weakness of left lower limb (distal to proximal).There was numbness and allodynia of right lower extremity, right half of abdomen and right sided chest wall with bladder bowel involvement. He had normal power and sensations in his upper extremities. The findings on general examination were unremarkable. Neurological examination revealed a normal mental state and intact cranial nerves. The power in the left lower extremity was grade 3/5 proximally and distally and normal in right lower extremity. Sensations to pin, and temperature were diminished $>50 \%$ below the D4 level of dermatome while Position and vibration sense was intact. Abdominal, Patellar and ankle reflexes were absent bilaterally, with extensor planter in left limb and equivocal in right limb. A working diagnosis of atypical BSS due to subacute cord compression with arachnoiditis was kept.

Laboratory examinations revealed complete blood count, liver and renal function test within normal limit. Chest, cervical spine radiographs and CT brain scan was normal. The CSF analysis revealed pleocytosis (60cells/mm3) with $95 \%$ lymphocytic count, increased total protein $(3800 \mathrm{mg} / \mathrm{dl})$, and decreased glucose $(40 \mathrm{mg} / \mathrm{dl})$. Tubercle bacillus (TB) was not detected in the CSF, although adenosine deaminase (ADA) was elevated (69.7 IU/l) in the CSF.

MRI spine post contrast T1 weighted [fig 1] showed a ring enhancing lesion (intramedullary) at D2-D3 level in the posterior half of the thecal sac slightly displacing the conus. On axial section [fig 2] the lesion is eccentric in location towards left side) might causing BSS. There were multiple IDEM tuberculoma in thoracic and cervical region with arachnoiditis. MRI brain showed no evidence of intracranial tuberculoma. He responded to high dose steroid and ATT. After one month of follow up, he could walk without support with no abnormal sensation of allodynia, numbness and improved bowel bladder symptoms. 


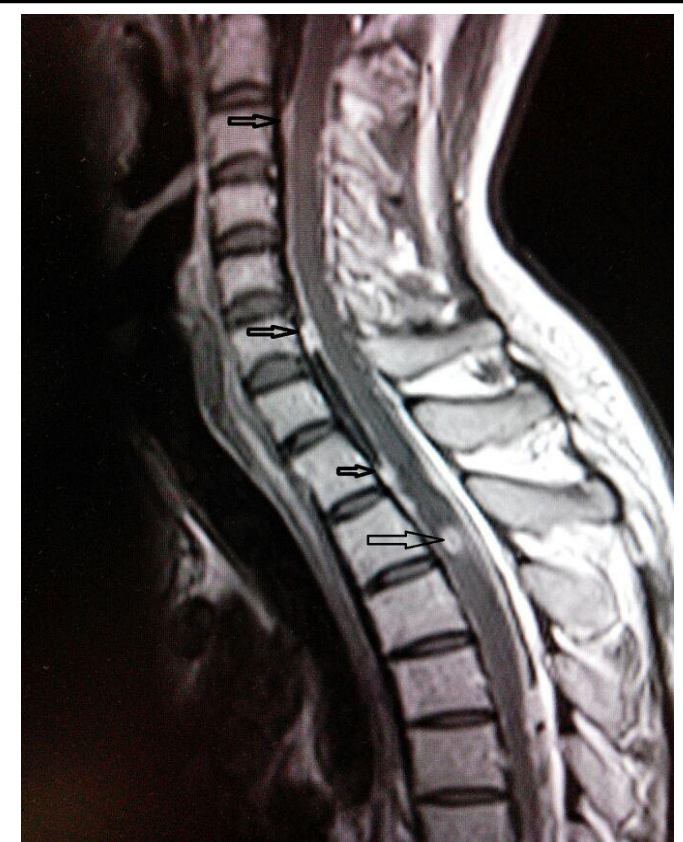

Fig. 1 MRI spine post contrast T1W showed a ring enhancing lesion (arrow with a thin border) in posterior half of the thecal sac. The lesion is intramedullary in location at D2-D3 level and appears to be displacing the conus. Also showing multiple intradural-extramedullary lesion in thoracic region and cervical region (arrow with thick border)

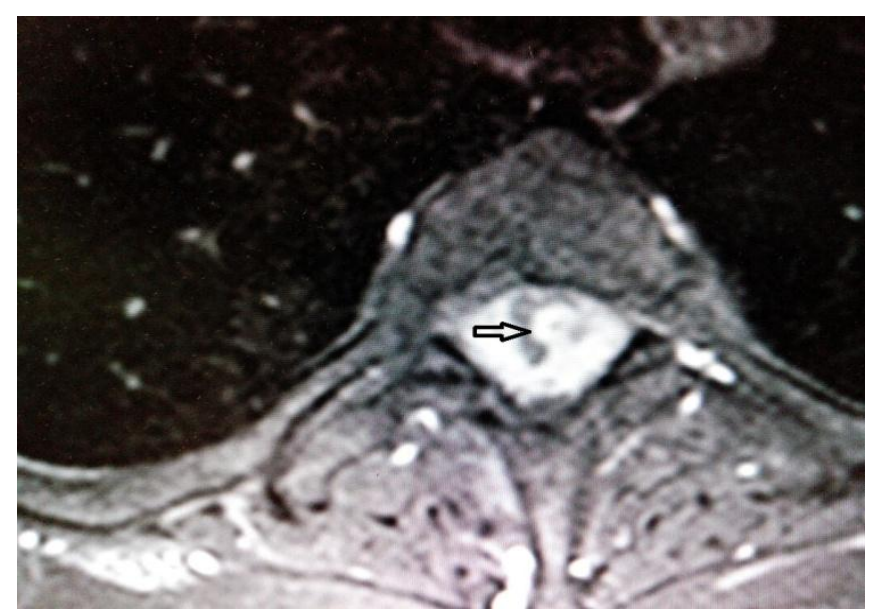

Fig. 2 On MRI spine axial section, the lesion (arrow) is eccentric in location (toward left side) which might cause Brown Sequard Syndrome.

\section{Discussion}

Spinal involvement in tuberculosis (TB) manifest in four ways: Pott's disease, nonosseous spinal tuberculoma (extradural, or (IDEM), or intramedullary location), spinal tuberculous meningitis, and tuberculous arachnoiditis; with nonosseous spinal tuberculoma being the rarest amongst them. ${ }^{(3)}$ Intramedullary tuberculomas is $\mathrm{a}$ is a rare form of tuberculosis with an incidence of only 2 of 100,000 cases of tuberculosis and 2 of 1000 cases of tuberculosis of central nervous systems disesase ${ }^{(2)}$ with IDEM location being the rarest amongst them. ${ }^{(3)}$ The lesions are so uncommon that they appear in the literature only as isolated case reports. ${ }^{(4,5,6,7)}$ Most cases had history of TBM and can occur as paradoxical response to ATT even up to 1 year of chemotherapy. ${ }^{(8)}$ The pathophysiology of the paradoxical response is thought to be a result of an immunological reaction. MacDonell et al. reviewed a total of 18 cases of intra-medullary tuberculomas of the spinal cord reported over a period of 30 years. $^{(9)}$ Intramedullary spinal tuberculomas commonly present as subacute spinal cord compression, with progressive lower limb weakness, paraesthesia and bladder bowel dysfunction. $^{(9)}$ It develops either due to hematogenous dissemination from a primary foci, or spinal fluid infection. Very few cases have been reported with co-occurrence of intramedullary and IDEM.

Since intraspinal tuberculomas produce a mass effect posing a risk to spinal cord function, surgical excision of the lesion is generally accepted. But there are cases treated with medical therapy alone. Parsons and Pallis have treated a case successfully with ATT and steroids alone ${ }^{(10)}$ as in our case. This case is being reported owing to its rarity of coexistence of intramedullary and IDEM tuberculoma. Moreover BSS can be a rare presentation of intramedullary tuberculoma and should be considered in the differential diagnosis of spinal cord compression in the absence of history of trauma.

Conflict of interest: none declared

Source of funding: nil

\section{References}

1. Citow JS, Ammirati M. Intramedullary tuberculoma of the spinal cord: Case report. Neurosurgery 1994:35:327-30. 
2. D. Balasa, A. Tunas, A. Terzi, C. Serban, M. Aschie Primary tuberculomas of the thoracal spinal cord. Case report Romanian Neurosurgery 2012 : XIX 1: $63-66$.

3. Shim DM, Oh SK, Kim TK, Chae SU. Intradural extramedullary tuberculoma mimicking en plaque meningioma. Clin Orthop Surg $2010: 2: 260-3$.

4. Bucy PC, Oberhill HR: Intradural spinal granulomas. J Neurosurg 1950; 7(1): 1-12.

5. Dastur HM: A tuberculoma review with some personal experiences. Part II: Spinal cord and its coverings. Neurol India 1972: 20(3): 127-131.

6. Garcia Allut A, Gelabert González M, Bollar Zabala A, Martinez Rumbo R, Reyes Santias R: Intradural extramedullar tuberculomaof spinal cord. Case report. J Neurosurg Sci 1985: 29 (2): 113-115.

7. Mathuriya SN, Khosla VK, Banerjee AK: Intradural extramedullary tuberculous spinal granulomas. Clin Neurol Neurosurg 1988: 90(2): 155-8.

8. Kumar R, Prakash M, Jha S. Paradoxical response to chemotherapy in neurotuberculosis. Pediatr Neurosurg 2006: 42: 214-222,

9. MacDonell AH, Baird RW, Bronze MS: Intramedullary tuberculomas of the spinal cord: case report and review. Clin Infect Dis 1990: 12:432-439.

10. Parsons M, Pallis CA: Intradural spinal tuberculomas. Neurol 1965: 15(11): 10181022. 